\title{
UYARLAMALI BULANIK MANTIK DENETLEYICİ TABANLI İNSANSIZ HAVA ARACI (İHA)'NIN ROTA TAKİBİ VE FAYDALI YÜK TAŞIMA PERFORMANSI
}

\author{
Egemen BELGE, Aytaç ALTAN, Rıfat HACIOĞLU* \\ Zonguldak Bülent Ecevit Üniversitesi, Mühendislik Fakültesi, Elektrik Elektronik Mühendisliği Bölümü, \\ Zonguldak, Türkiye
}

\begin{tabular}{ll}
\hline Anahtar Kelimeler & Öz \\
\hline Insansız Hava Aracı, & Otonom olarak hareket eden İnsansız Hava Araçlarında (İHA) yük taşıma sistemi \\
Yük Taşıma Sistemi, & sivil ve askeri alanlarda sıklıkla kullanılmaktadır. Coğrafi koşulların elverişsiz \\
Rota Takibi, & olduğu operasyon bölgelerinde belirlenen konumdan alınan faydalı yükün belirli bir \\
Bulanık PID, & rota takip edilerek hedeflenen konuma minimum hata ile bırakılması büyük önem \\
Faydalı Yük. & arz etmektedir. Bu tür görevlerin başarıyla gerçekleştirilebilmesi için İHA'nın \\
& belirlenen rotayı minimum hata ile takip etmesi gerekmektedir. Bu çalışmada, yük \\
& alma bırakma sistemi kullanılarak belirlenen bölgedeki farklı renkli iki özdeş faydalı \\
& yükün dört pervaneli İHA tarafından sırasıyla alınarak belirlenen konuma bir rota \\
& üzerinden minimum hata ile bırakllabilmesi için bulanık PID denetleyicisi \\
& tasarlanmaktadır. Faydalı yük alma, taşıma ve bırakma görevi esnasında elde edilen \\
& sonuçlar PID denetleyici performansı ile kıyaslamalı olarak analiz edilmektedir. \\
\hline
\end{tabular}

\section{ROUTE TRACKING AND PAYLOAD TRANSPORTATION PERFORMANCE OF ADAPTIVE FUZZY LOGIC CONTROLLER BASED UNMANNED AERIAL VEHICLE (UAV)}

\begin{tabular}{l}
\hline Keywords \\
\hline Unmanned Aerial Vehicle, \\
Load Transportation System, \\
Route Tracking, \\
Fuzzy PID, \\
Payload.
\end{tabular}

Payload.

\begin{abstract}
In autonomous unmanned aerial vehicles (UAV), the payload transporting system is frequently used in civil and military areas. It is very important that the payload taken from the predetermined location in the operational regions where the geographical conditions are unfavorable is left to the target location with minimum error by tracking a certain route. In order to perform such tasks successfully, the UAV must follow the specified route with minimum error. In this study, two identical payloads of different color in the predetermined region are taken by the UAV respectively, and transported to the target location with minimum error by tracking the defined route. A fuzzy PID controller is designed to perform this task. The results obtained during the payload hold, transport and release task are analyzed in comparison with PID controller performance.
\end{abstract}

Alıntı / Cite

Belge, E., Altan, A., Hacıoğlu, R., (2021). Uyarlamalı Bulanık Mantık Denetleyici Tabanlı İnsansız Hava Aracı (İHA)'nın Rota Takibi ve Faydalı Yük Taşıma Performansı, Mühendislik Bilimleri ve Tasarım Dergisi, 9(1), 116125.

\begin{tabular}{l|l|l}
\hline Yazar Kimliği / Author ID (ORCID Number) & \multicolumn{3}{|l}{ Makale Süreci / Article Process } \\
\hline E. Belge, 0000-0001-5852-1085 & Başvuru Tarihi / Submission Date & 06.05 .2020 \\
A. Altan, 0000-0001-7923-4528 & Revizyon Tarihi / Revision Date & 21.12 .2020 \\
R. Hacıŏlu, 0000-0002-2480-0729 & Kabul Tarihi / Accepted Date & 14.01 .2021 \\
& Yayım Tarihi / Published Date & 30.03 .2021 \\
\hline
\end{tabular}

\section{Giriş (Introduction)}

Coğrafi koşulların elverişsiz ve insanlı uçuşun riskli olduğu bölgelerde bulunan hedeflere faydalı yüklerin taşınması günümüzde sivil ve askeri çalışmalar için büyük önem arz etmektedir (Lee, 2017). Faydalı yüklerin belirlenen koordinattan alınarak bir veya birden fazla hedef konuma bırakılmasında İnsansız Hava Araçları (İHA) ön plana çıkmaktadır (Altan, vd., 2018). Faydalı yüklerin belirlenen hedeflere minimum hata ile taşınabilmesi için İHA'ların etkin denetimi önemli bir mühendislik problemi olarak karşımıza çıkmaktadır (Altan, vd., 2018; Shirani,

\footnotetext{
* ilgili yazar / Corresponding author: hacirif@beun.edu.tr, +90-372-291-2551
} 
vd., 2019). Bu çalışmada, belirli bir rota takip edilerek yük alma ve bırakma problemi için yük taşıma sistemine sahip İHA'nın denetimi bulanık Propotional-Integral-Derivative (PID) denetleyici ile gerçekleştirilmektedir. Yük alma ve bırakma görevi için önerilen denetleyici ile PID denetleyicinin performansı kıyaslanmaktadır.

Literatürdeki çalışmalar incelendiğinde, İHA'ların faydalı yük taşıma ve bu yükleri belirlenen bir rotayı takip ederek hedeflere bırakmaları konusunda son zamanlarda birçok çalışmanın yapıldığı görülmektedir. İHA’ların rota takibi problemlerinin çözülmesinde çeşitli denetleyiciler önerilmektedir (Tavakol ve Binazadeh, 2017; Rego ve Raffo, 2019; Liu, vd., 2018). Dört pervaneli bir İHA'nın rota takibi probleminin çözümünde, ayrışmamış mekanik sistemler için doğrusal olmayan gürbüz bir kontrol algoritması önerilmektedir. Önerilen algoritmada, İHA'nın iç döngüdeki konumunun denetimi için altı serbestlik dereceli dinamik modele dayanan doğrusal olmayan $\mathcal{H}$ denetleyicisi kullanılmaktadır. Referans yörüngenin takibi modele dayalı denetleyici ile gerçekleştirilmektedir (Raffo, vd., 2011). Dört pervaneli İHA'nın rota takibi için denetimi kazanç-zamanlama PID kontrol yaklaşımı ile gerçekleştirilmektedir. İnterpolasyon algoritması ile önerilen denetleyicinin parametreleri optimize edilerek belirlenmektedir. İHA'nın çalışma koşullarının büyük ölçüde ve hızlı bir șekilde değișebileceği durumlar için önerilen denetleyiciye bir dizi önceden ayarlanmış PID denetleyici kazanç katsayıları uygulanmaktadır (Qiao, vd., 2018). Faydalı yükler belirli rota takip edilerek İHA üzerine monte edilen yük alma-bırakma sistemiyle veya İHA gövdesine asılı kablolar ile taşınabilmektedir. Faydalı yüklerin İHA'nın gövdesine asılı kablo ile taşınması serbestlik derecesinin artmasına, İHA'nın gövdesine monte edilen yük alma-bırakma sistemi ile taşınması ise yük ataletinin artmasına neden olmaktadır (Villa, vd., 2019). Bu faydalı yük taşıma görevinin başarıyla gerçekleștirebilmesi hem İHA'nın hem de yük tașıma sisteminin denetleyici performansı ile doğrudan ilişkilidir (Altan ve Hacıoğlu, 2020). Dört pervaneli bir İHA'ya asılı yük taşıma sisteminin konum ve salınım hareketinin denetimi için enerji metodolojisine dayalı lineer olmayan uyarlamalı denetleyici stratejisi önerilmektedir. Kapalı devre sistemin kararlılı̆̆ı, İHA'nın pozisyon hatasının asimptotik yakınsaması ve yük salınımının azaltılması Lyapunov tabanlı kararlılık analizi ile ifade edilmektedir (Xian, vd., 2019).

Bu çalışmada, dört pervaneli İHA'nın belirli bir rotayı takip ederek yük alma ve bırakma görevini minimum hata ile yerine getirebilmesi için bulanık PID denetleyici önerilmektedir. Önerilen denetleyicinin tasarımında dört pervaneli İHA'nın matematiksel modelinden faydalanılmaktadır. Önerilen denetleyicinin performansı PID performansı ile kıyaslanmaktadır. Çalışmada, dört pervaneli İHA'nın belirli bir rotayı takip ederek yük alma ve bırakma görevi için önerilen denetleyici algoritması II. bölümde açıklanmakta, önerilen bulanık PID denetleyicisi ile elde edilen benzetim sonuçları III. bölümde verilmekte ve önerilen denetleyici için elde edilen sonuçlar IV. bölümde tartışılmaktadır.

\section{Dört Pervaneli İHA' nın Bulanık PID Denetimi (Fuzzy PID Control of UAV)}

Bu çalışmada dört pervaneli İHA’nın iki farklı noktadan yük alma bırakma görevi için Bulanık PID denetleyicisi önerilmektedir. Bu bölümde İHA sistem modeli ile klasik PID denetleyicisi tasarımı ve önerilen bulanık denetleyicinin, referans rotayı takip edebilme hatası, bulanık mantık kuralları, giriş çıkış üyelik fonksiyonları ve bulanık PID katsayılarının matematiksel ifadeleri tanımlanmaktadır.

\subsection{Dört Pervaneli İHA'nın Sistem Modeli (System Model of UAV)}

Dört pervaneli İHA için, Euler yuvarlanma, yunuslama ve sapma açıları gövde $\{g\}$ ve genel çerçeve $\{G\}$ üzerinde durum denklemleri $X, Y, Z$ (kuzey, doğu, aşağı) yönü, $x, y, z$ gövde (kuzey, doğu, aşağı) yönü ve $\phi, \theta, \psi$ (yuvarlanma, yunuslama ve sapma) açıları Şekil 1'de gösterilmektedir.

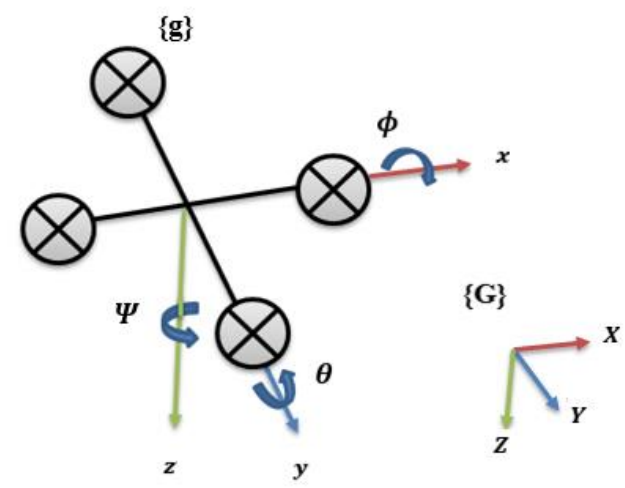

Şekil 1. Dört pervaneli İHA’nın dönme hareketi (Rotational movement of quadrotor UAV)

Dört Pervaneli İHA'nın denetiminde kullanılan hareket eşitlikleri (1) ve (2) 


$$
\begin{gathered}
{\left[\begin{array}{c}
\ddot{X} \\
\ddot{Y} \\
\ddot{Z}
\end{array}\right]=\frac{-1}{m}\left[\begin{array}{ccc}
K_{d x} & 0 & 0 \\
0 & K_{d y} & 0 \\
0 & 0 & K_{d z}
\end{array}\right]\left[\begin{array}{l}
\dot{X} \\
\dot{Y} \\
\dot{Z}
\end{array}\right]-\frac{1}{m}\left[\begin{array}{c}
c(\phi) s(\theta) c(\psi)+s(\phi) s(\psi) \\
c(\phi) s(\theta) s(\psi)-s(\phi) c(\psi) \\
c(\phi) c(\theta)
\end{array}\right] u_{1}+\left[\begin{array}{l}
0 \\
0 \\
g
\end{array}\right]} \\
{\left[\begin{array}{c}
\dot{\phi} \\
\dot{\theta} \\
\dot{\psi}
\end{array}\right]=\left[\begin{array}{ccc}
1 & s(\phi) t(\theta) & t(\phi) t(\theta) \\
0 & c(\phi) & -s(\phi) \\
0 & s(\phi) / c(\theta) & c(\phi) / c(\theta)
\end{array}\right]\left[\begin{array}{l}
p \\
q \\
r
\end{array}\right]} \\
{\left[\begin{array}{c}
\dot{p} \\
\dot{q} \\
\dot{r}
\end{array}\right]=\left[\begin{array}{l}
\frac{\left(I_{z}-I_{y}\right)}{I_{x}} q r \\
\frac{\left(I_{x}-I_{z}\right)}{I_{y}} r p \\
\frac{\left(I_{y}-I_{x}\right)}{I_{z}} p q
\end{array}\right]+\left[\begin{array}{c}
\frac{-J_{T P}}{I_{x}} q \\
\frac{J_{T P}}{I_{y}} p \\
0
\end{array}\right] \Omega+\left[\begin{array}{ccc}
\frac{l}{I_{x}} & 0 & 0 \\
0 & \frac{l}{I_{y}} & 0 \\
0 & 0 & \frac{1}{I_{z}}
\end{array}\right]\left[\begin{array}{l}
u_{2} \\
u_{3} \\
u_{4}
\end{array}\right]}
\end{gathered}
$$

ile ifade edilmektedir (Ryll, vd., 2014). Eșitlik (1)'de $u_{1}$, motorların toplam itkisi; $m$, çok rotorlu İHA'nın kütlesine; $\phi$, yalpalama açısına; $\theta$, yunuslama açısına; $\psi$, sapma açısına; $s$, sinus fonksiyonuna; $c$, kosinüs fonksiyonuna ve $g$ yerçekimi ivmesine karşılık gelmektedir. Eşitlik (2)'de $p, q, r$ sırasıyla yalpalama, yunuslama ve sapma açısal hızlarını ifade etmekte olup $t$, tanjant fonksiyonunu belirtmektedir. Eşitlik (3)'de ise $I_{x}, I_{y}$ ve $I_{z}$, her bir eksen etrafındaki eylemsizlik momentine; $J_{T P}$, motorun dönmesinden kaynaklanan eylemsizlik momentine; $u_{2}$, yalpalama açısı girdisine; $u_{3}$, yunuslama açısı girdisine; $u_{4}$, sapma açısı girdisini ifade etmektedir. Bu benzetim çalışmasında, Eşitlik (1-3)'de çok rotorlu İHA'nın kütlesi $(m)$ ile eylemsizlik moment katsayıları yük alma ve bırakma sırasında değişim göstermektedir.

\subsection{Rota Takibi (Route Tracking)}

Çok rotorlu İHA'nın insansız olarak hareketini sağlamak, istenen rotaya en kısa sürede gitmesini ve yüksek enerji verimliliği amacıyla rota takibi yapması ve istenilen rotada hareketinin sağlanması büyük önem teşkil etmektedir. Rota takibinin yapılması için çok rotorlu İHA'nın belirtilen rotaya ilerlemesi veya kendi rotasını belirli algoritmalarla ve yöntemlerle oluşturması gerekmektedir. Çok rotorlu İHA'nın belirlenen rotayı takip etmesiyle ilgili literatürde pek çok çalışma bulunmaktadır (Altan, vd., 2018; Rego ve Raffo, 2019; Raffo, vd., 2011). Tüm rota takip sistemlerinde referans noktaları belirlenmekte ve İHA'nın referansı takip etme oranı incelenmektedir. Buna göre rota takibinde $x_{d}, y_{d}, z_{d}$ referans rotayı belirtecek olursa $x, y, z$ İHA'nın rotasını göstermektedir. Bu durumda hata, Eşitlik (4) ile

$$
e=\sqrt{\left(x_{d}-x\right)^{2}+\left(y_{d}-y\right)^{2}+\left(z_{d}-z\right)^{2}}
$$

ifade edilmektedir.

\subsection{Denetleyici Tasarımı (Controller Design)}

PID denetleyicisi kapalı döngü geri bildirim sistemi olarak bilinmektedir. Kontrol sistemi, gerçek ve istenen durum arasındaki farkı hesaplamakta ve bir hata değeri üretmektedir. Çok rotorlu İHA üzerinde bulunan sensörden çıkan ölçüm değerleri, bu hata sinyalini hesaplamak için geri beslenerek istenen değer ile ölçülen değer arasındaki dengeyi sağlamaktadır (Pounds, vd., 2012). PID kontrol sisteminin çıkışı, sistemi istenen duruma yaklaştıracak bir kontrol değeridir. PID denetleyicisi, parametre kazançlarının kolay ayarlanması, tasarımı ve dayanımı açısından avantajlıdır; ancak matematiksel model ile ilişkilendirilen doğrusal olmayan ve kesin durumlar içermeyen çok rotorlu İHA modellerinde, İHA'nın hareketini ve performansını sınırlandırmaktadır. PID denetleyicisiyle denetlenen İHA'nın kontrol girişi $u(t), K_{P}$ : oransal kontrol kazancl, $K_{I}$ : integral kontrol kazancl, $K_{D}$ : türevsel kontrol kazancı ve $t$ : anlık zaman değişkeni Eșitlik (5)'de

$$
u(t)=K_{P} e(t)+K_{I} \int_{0}^{t} e(\tau) d \tau+K_{D} \dot{e}(t)
$$

olduğu gibi ifade edilmektedir ki burada hata $e(t)$ dir. PID denetleyici kazanç parametreleri $K_{P}, K_{I}, K_{D}$, İHA'nın dinamik modeline göre Ziegler-Nichols yaklaşımı ile elde edilmektedir. Öncelikle basamak cevabına oransal denetleyici kazancı kararlılık sınırında artırılarak $K_{u}$ ve $T_{u}$ değerleri elde edilmekte olup $K_{P}=0.6 K_{u}, K_{I}=1.2 K_{u} / T_{u}$, $K_{D}=0.075 K_{u} T_{u}$ ilişkisi ile PID paremetreleri hesaplanabilmektedir. Burada pozisyon $X, Y, Z$ ve açısal hız $p, q, r$ için PID kullanılırken yönelme açıları için P denetleyici kullanılmaktadır. En yüksek aşım \%15 değerini aşmayacak şekilde kararlılık ve doğrusal olmayan system dinamiği değerlendirilerek yükselme $Z$ için $K_{u}=11.76$ ve $T_{u}=2.73$ olarak bulunmakta ve $K_{P}=7.06, K_{I}=5.17, K_{D}=2.04$ kullanılmaktadır. Pozisyon $X, Y$, için $K_{u}=0.6$ ve $T_{u}=7$ olarak 
bulunmakta ve $K_{P}=0.35, K_{I}=0.1, K_{D}=0.31$ kullanılmaktadır. Açısal hız $p, q, r$ için ise $K_{u}=4.1$ ve $T_{u}=0.03$ olarak bulunmakta ve $K_{P}=2.7, K_{I}=1, K_{D}=0.01$ kullanilmaktadır.

Dört pervaneli İHA'nın bulanık PID denetimi Şekil 2'de blok şema ile gösterilmektedir. İHA'nın PID katsayıları belirlenen kural tabanına göre uyarlamalı olarak güncellenmektedir. İHA'nın istenilen $X_{d}, Y_{d}, Z_{d}$ konumları ve elde edilen $X, Y, Z$ konumları arasındaki hata ve hata değişiminin üyelik fonksiyonları bulanık mantık denetleyicisine giriş olarak verilmektedir.

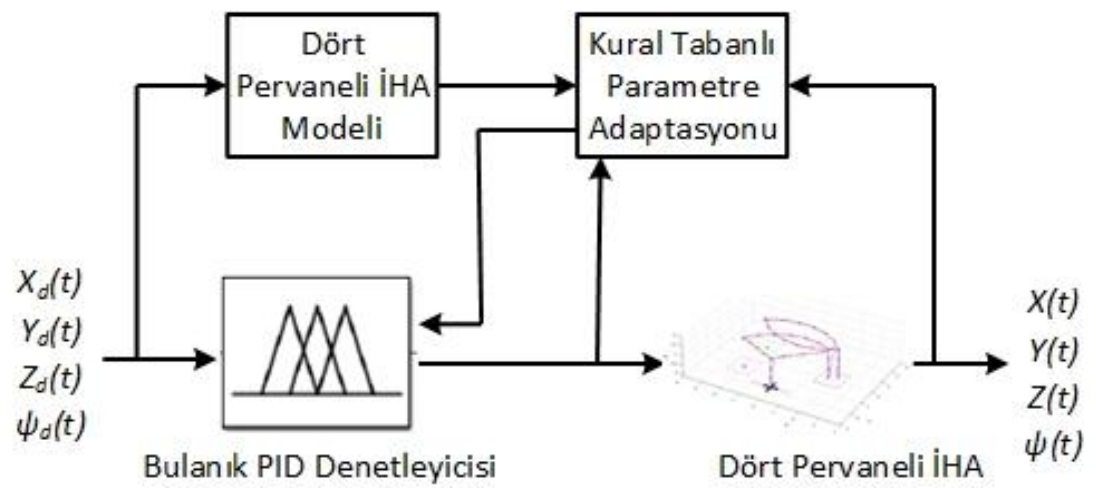

Şekil 2. Dört pervaneli İHA'nın bulanık PID denetimi (Fuzzy PID control of quadrotor)

Bu çalışmada PID katsayılarının doğrudan hesaplanmasında önerilen bulanık PID yaklaşımında referans konum ve İHA'nın konumu arasındaki hata $(e)$ ve hata değişimine $(d e)$ göre $K_{P}, K_{D}$ değerlerini ve bağlı olarak $K_{I}$ değerlerinin elde edilebildiği bulanık denetleyicisinin Şekil 3'te giriş ve Şekil 4'te çıkış üyelik fonksiyonları gösterilmektedir. Şekil 4'te $N$ (Negatif), $P$ (Pozitif), $B$ (Büyük), $M$ (Orta), $S$ (Küçük), $Z O$ (Sıfır) olarak belirtilirse, giriş üyelik fonksiyonları hız hatası ve hız hatasının değişimi için $N B, N M, N S, Z O, P S, P M, P B$ olarak, çıkış üyelik fonksiyonları $K_{P}, K_{D}$ ve $\alpha$ ile ifade edilmektedir. Buna göre PID katsayıları Eşitlik (6-11)'e göre hesaplanmaktadır. Burada kullanılan $K_{\text {pmin }}$ ve $K_{\text {pmaks }}$ değerleri $K_{P}$ 'nin, $K_{d m i n}$ ve $K_{d m a k s}$ değerleri $K_{D}$ 'nin sirasıyla minimum ve maksimum değerlerini ifade etmektedir (Gao ve Liu, 2016).

$$
\begin{aligned}
K_{P} & =K_{\text {pmin }}+\left(K_{\text {pmaks }}-K_{\text {pmin }}\right) * K_{P}^{\prime} \\
K_{D} & =K_{\text {dmin }}+\left(K_{\text {dmaks }}-K_{\text {dmin }}\right) * K_{D}^{\prime} \\
K_{I} & =\frac{K_{P}{ }^{2}}{\alpha K_{D}} \\
K_{P}^{\prime} & =\sum_{i=1}^{1} \mu_{i} K_{P, i}{ }^{\prime} \\
K_{D}^{\prime} & =\sum_{i=1} \mu_{i} K_{D, i}{ }^{\prime} \\
\alpha & =\sum_{i=1} \mu_{i} \alpha_{i}
\end{aligned}
$$

$K_{P}^{\prime}, K_{D}^{\prime}, \alpha$ parametrelerinin bulanık mantık kuralları sırasıyla Tablo 1,2 ve 3 'de verilmektedir. $K_{P}^{\prime}$ ve $K_{D}^{\prime}$ değerleri sırasıyla $K_{P}$ ve $K_{D}$ değerlerinin 0 ile 1 arasına normalize edilmiş halidir. Eşitlik (8)'de ifade edildiği gibi $\alpha$ parametresi integral kazancının hesaplanmasında kullanılan bir katsayıdır. Kararlılık ve doğrusal olmayan system dinamiği değerlendirilerek yükselme $Z$ için $K_{p m i n}=6, K_{p m a k s}=8, K_{d m i n}=1.6, K_{d m a k s}=3.2$, pozisyon $X, Y$, için $K_{p m i n}=$ $0.2, K_{\text {pmaks }}=0.45, K_{d m i n}=0.2, K_{d m a k s}=0.45$, ve açısal hız $p, q, r$ için ise $K_{p m i n}=2.2, K_{p m a k s}=3.2 K_{d m i n}=0, K_{d m a k s}=0.02$ olarak kullanılmaktadır.

Tablo 1. $K_{p}^{\prime}$ için bulanık mantık kuralları (Fuzzy logic rules for $K_{p}^{\prime}$ )

\begin{tabular}{ccccccccc}
\hline & \multicolumn{8}{c}{ de (Hata Değişimi) } \\
\cline { 3 - 8 } $\boldsymbol{5}$ & NB & NM & NS & ZO & PS & PM & PB \\
\hline \multirow{5}{*}{ (Hata) } & NB & B & B & B & B & B & B & B \\
& NM & S & B & B & B & B & B & S \\
& NS & S & S & B & B & B & S & S \\
& ZO & S & S & S & B & S & S & S \\
& PS & S & S & B & B & B & S & S \\
& PM & S & B & B & B & B & B & S \\
& PB & B & B & B & B & B & B & B \\
\hline
\end{tabular}


Tablo 2. $K_{d}^{\prime}$ için bulanık mantık kuralları (Fuzzy logic rules for $K_{d}^{\prime}$ )

\begin{tabular}{lllllllll}
\hline & \multicolumn{8}{c}{$\boldsymbol{d e}$ (Hata Değişimi) } \\
\cline { 3 - 8 } & & NB & NM & NS & ZO & PS & PM & PB \\
\hline \multirow{5}{*}{$\boldsymbol{e}$ (Hata) } & NB & S & S & S & S & S & S & S \\
& NM & B & B & S & S & S & B & B \\
& NS & B & B & B & S & B & B & B \\
& ZO & B & B & B & B & B & B & B \\
& PS & B & B & B & S & B & B & B \\
& PM & B & B & S & S & S & B & B \\
& PB & S & S & S & S & S & S & S \\
\hline
\end{tabular}

Tablo 3. $\alpha$ için bulanık mantık kuralları (Fuzzy logic rules for $\alpha$ )

\begin{tabular}{lllllllll}
\hline & & \multicolumn{7}{c}{$\boldsymbol{d e}$ (Hata Değişimi) } \\
\cline { 3 - 9 } & NB & NM & NS & ZO & PS & PM & PB \\
\hline \multirow{5}{*}{$\boldsymbol{*}$ (Hata) } & NB & 2 & 2 & 2 & 2 & 2 & 2 & 2 \\
& NM & 3 & 3 & 2 & 2 & 2 & 3 & 3 \\
& NS & 4 & 3 & 3 & 2 & 3 & 3 & 4 \\
& ZO & 5 & 4 & 3 & 3 & 3 & 4 & 5 \\
& PS & 4 & 3 & 3 & 2 & 3 & 3 & 4 \\
& PM & 3 & 3 & 2 & 2 & 2 & 3 & 3 \\
& PB & 2 & 2 & 2 & 2 & 2 & 2 & 2 \\
\hline
\end{tabular}
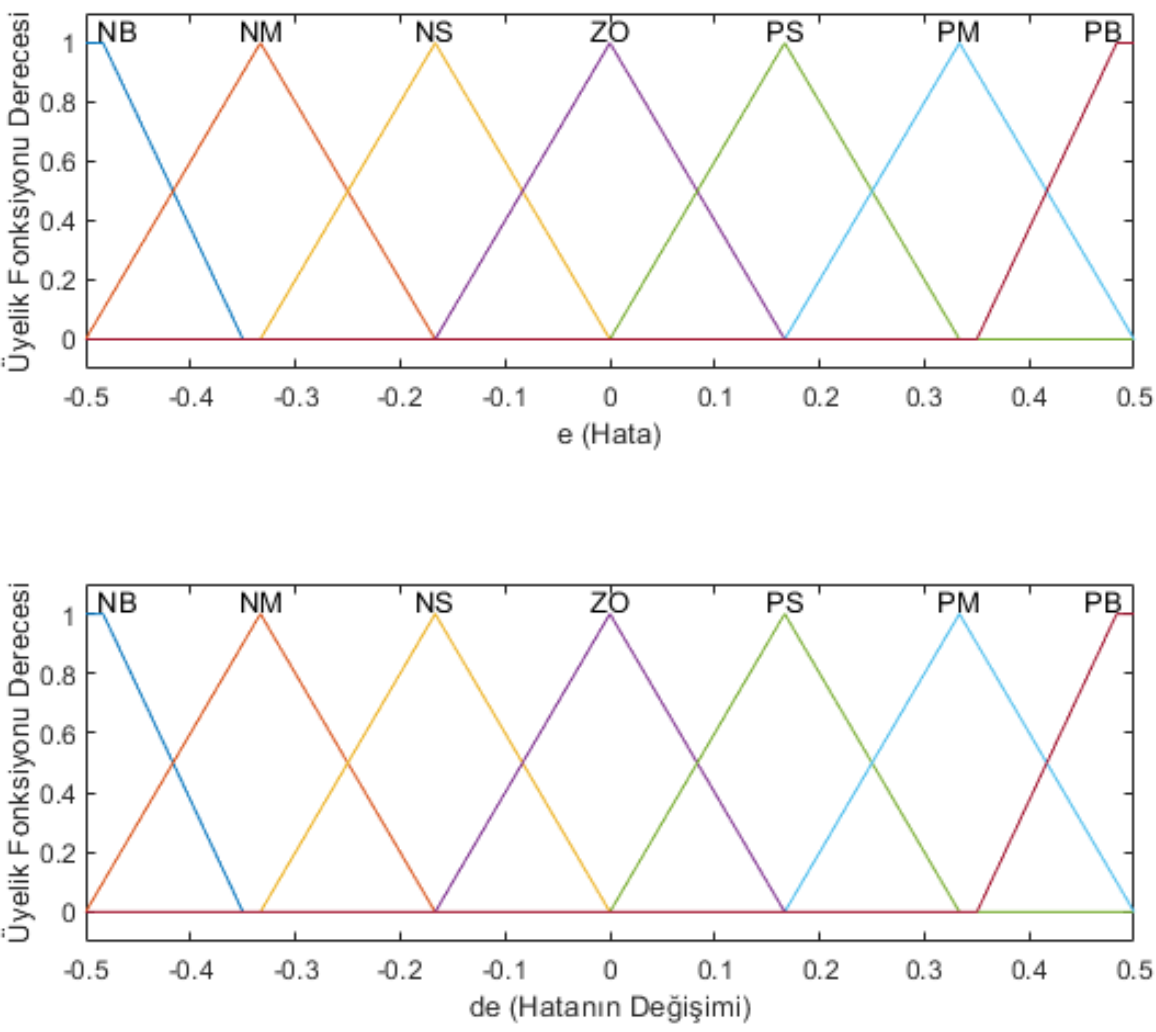

Şekil 3. Giriş üyelik fonksiyonları (Input membership functions) 

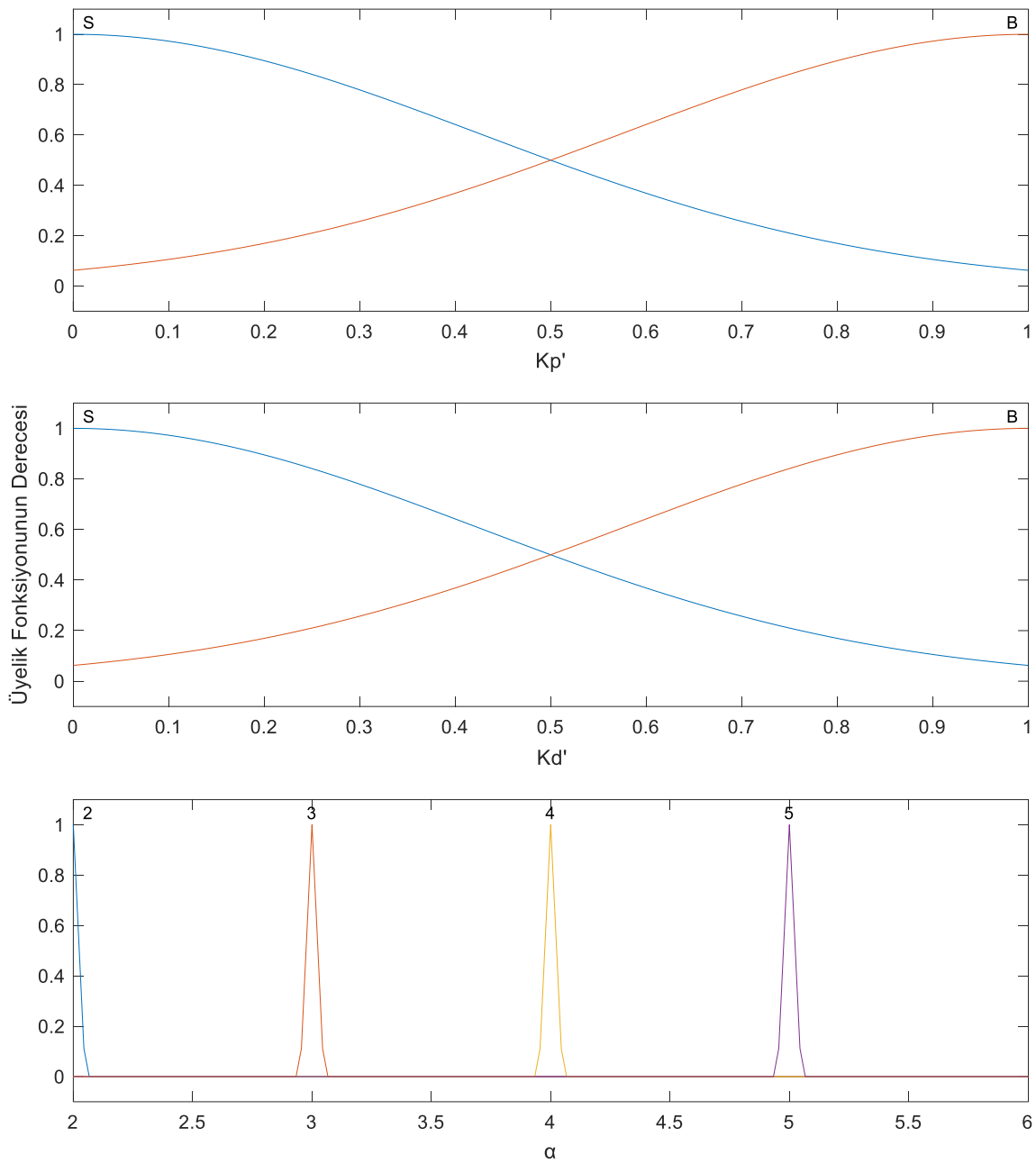

Şekil 4. Çıkış üyelik fonksiyonları (Output membership functions)

\section{Rota Takibi Sonuçları (Route Tracking Results)}

Kalkış noktasından kalkan İHA'nın yük alma alanındaki 1'inci yükü aldıktan sonra Rota 1'i takip ederek yükü yeşil alana bırakması, 1'inci yükü ilgili hedef noktasına bırakan İHA'nın yük alma alanındaki 2'nci yükü aldıktan sonra Rota 2'yi izleyerek pembe alana bırakması Şekil 5'te gösterilmektedir. Şekil 5'te İHA'nın takip ettiği güzergah noktaları kırmızı yıldız işaretiyle gösterilmektedir. Bu çalışmada İHA'nın boş ağırlı̆̆ı 1.5 kg, 1'inci yükün ağırlığı 1 kg ve 2'inci yükün ağırlığı 1.25 kg'dır. İHA'nın 1'inci yükü alması ve bırakması sırasıyla 17 ve 35 'inci saniyelerde gerçekleşmektedir. İHA'nın 2'inci yükü alması ve bırakması sırasıyla 53 ve 69'uncu saniyelerde gerçekleşmektedir. İki konum arasında yük taşıma işlemini gerçekleştiren İHA kalkış yaptığı noktaya inerek görevini tamamlamaktadır. İHA'nın rota takibinde iki farklı denetleyici için aldığı toplam yol ve hata değerleri kıyaslamalı olarak Tablo 4'de verilmektedir. Sistemin örnekleme aralığı 0.01 s'dir. İHA'nın rota takibinde kullanılan PID ve bulanık PID denetleyicileri için toplam karesel hata $9.0849 \mathrm{~m}^{2}$ ve $4.8798 \mathrm{~m}^{2}$, toplam alınan yol $31.5972 \mathrm{~m}$ ve $31.3844 \mathrm{~m}$ olarak sırasıyla elde edilmektedir. Şekil 6'da IHA'nın rota takibinde PID ve bulanık PID denetleyicilerinin $X, Y, Z$ yönlerindeki referans pozisyona göre değișimleri ve karesel hata değerinin zamana göre değişimi gösterilmektedir. Şekil 7'de İHA'nın yük alma bırakma süreçlerinde motor hızları (w1-w4), yükseklik kontrol değiş̧keni $\left(\mathrm{U}_{1}\right)$ ve yönelim kontrol değişkenleri $\left(\mathrm{U}_{2}-\mathrm{U}_{4}\right)$ gösterilmektedir. Motor hızları, yükseklik kontrol değişkenindeki değişimler incelendiğinde 1'inci yükün alınması ve bırakması sırasıyla 17 ve 35 'inci saniyelerde, 2'inci yükün alınması ve bırakılması ise 53 ve 70 'inci saniyelerde gerçekleştiği gözlemlenmektedir. Elde edilen sonuçlar göz önünde bulundurulduğunda önerilen bulanı PID denetleyicisinin, belirli bir rotayı takip ederek yük alma ve bırakma görevini gerçekleștiren dört pervaneli İHA'nın $X, Y, Z$ yönlerindeki referans rotayı takip edebilme performansı klasik PID yöntemine göre yüksektir. Bu duruma bağlı olarak bulanık PID denetleyicisinin karesel hatası ve İHA'nın rota takibi süresince aldı̆̆ı toplam yol PID denetleyicisine göre daha düşüktür. 
Tablo 4. Rota takibinde kullanılan denetleyicilerin performans analizi (Performance analysis of controllers used in route tracking)

\begin{tabular}{ccc}
\hline Performas Kriteri & $\begin{array}{c}\text { PID } \\
\text { Denetleyicisi }\end{array}$ & $\begin{array}{c}\text { Bulanık PID } \\
\text { Denetleyicisi }\end{array}$ \\
\hline Karesel Hata $\left(\mathrm{m}^{2}\right)$ & 9.0849 & 4.8798 \\
\hline $\begin{array}{c}\text { Toplam Yol }(\mathrm{m}) \\
(\text { Referans Rota }=27.93 \mathrm{~m})\end{array}$ & 31.5972 & 31.3844 \\
\hline
\end{tabular}

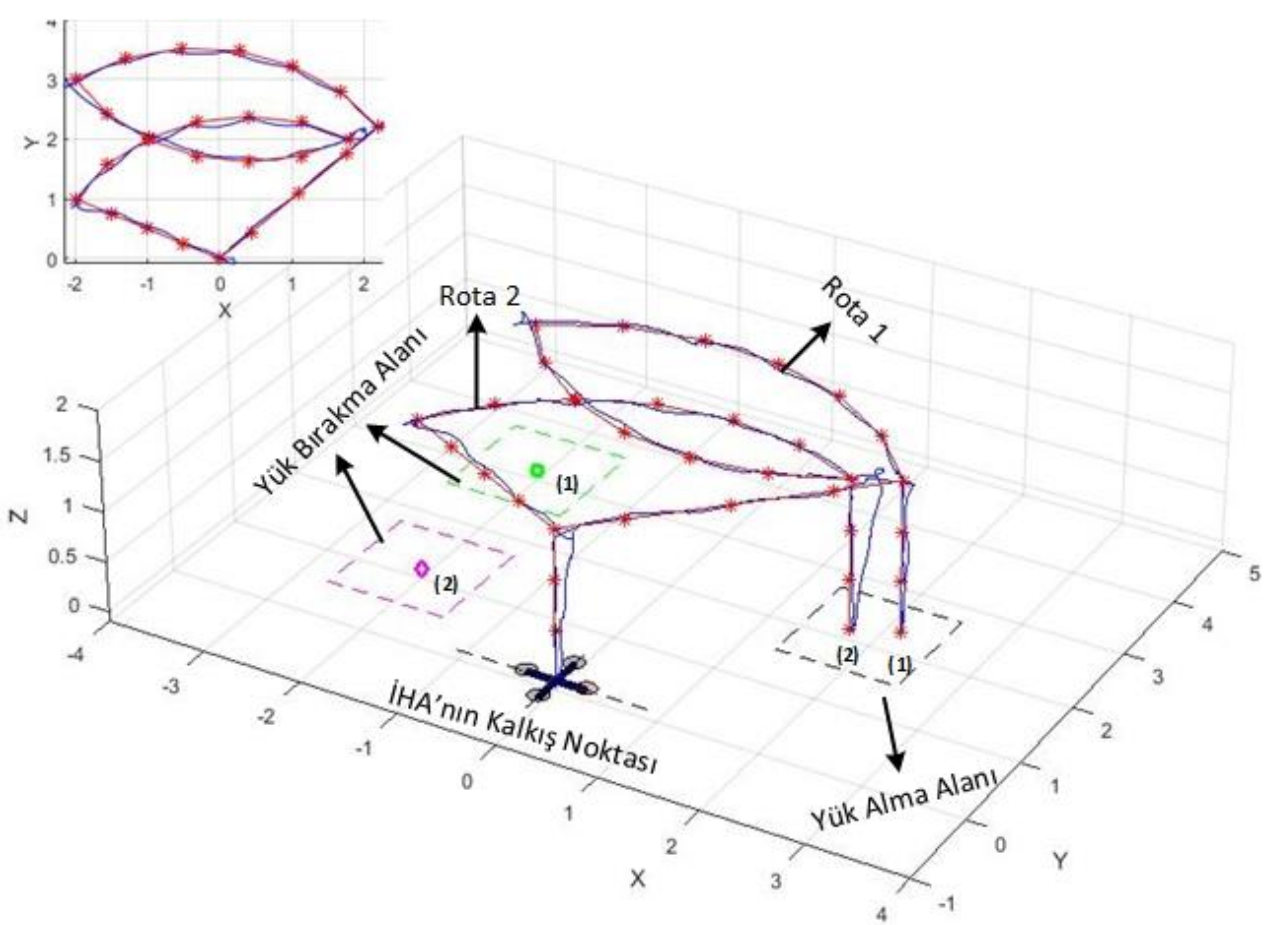

Şekil 5. İHA'nın bulanık PID denetleyicisi ile rota takibi (Route tracking with fuzzy PID controller of UAV) 

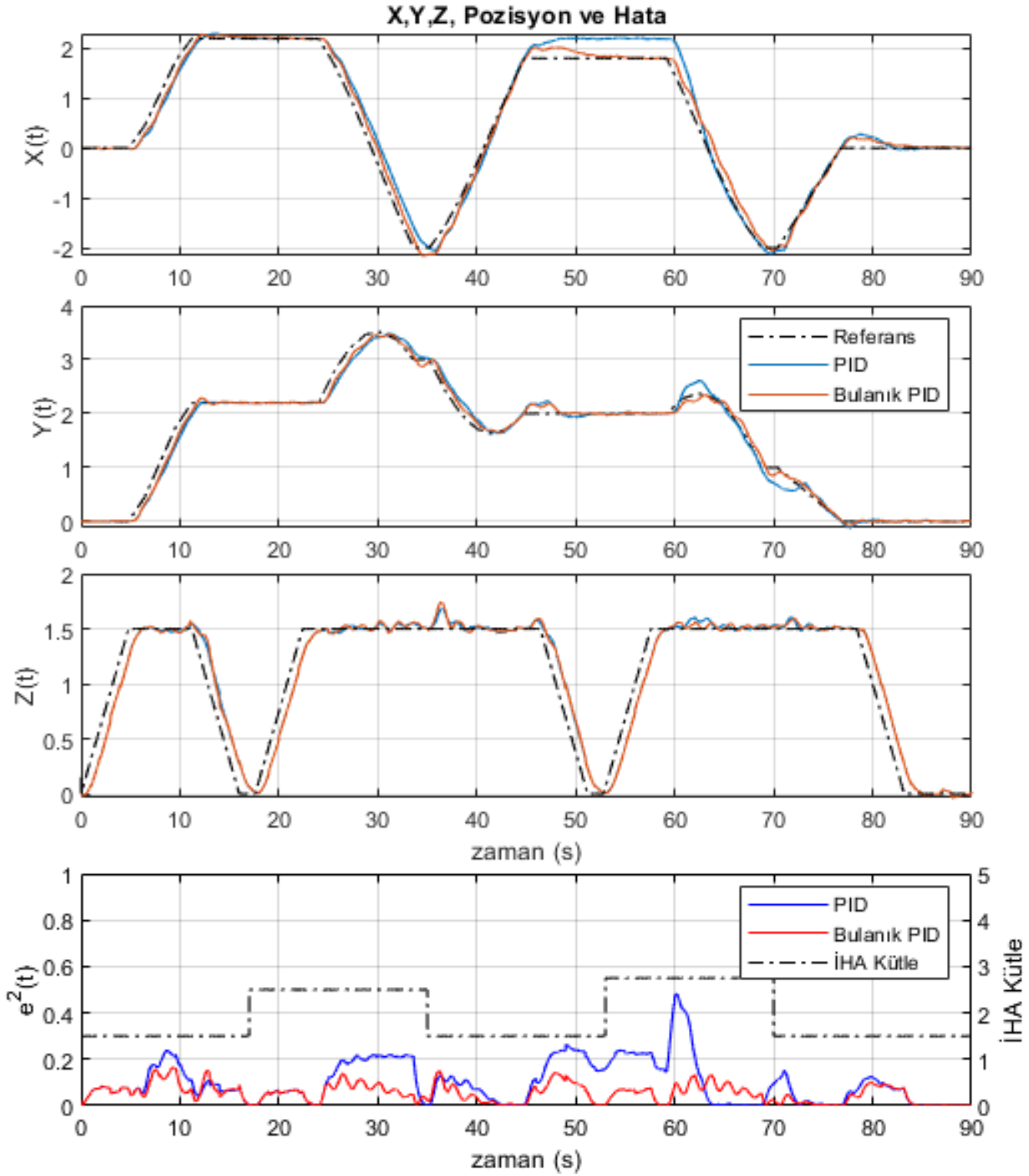

Şekil 6. İHA'nın faydalı yük etkisi ile rota takibinde X, Y, Z pozisyon ve karesel hata değişimi (X, Y, Z position and squared error change in the route tracking of UAV with payload effect) 

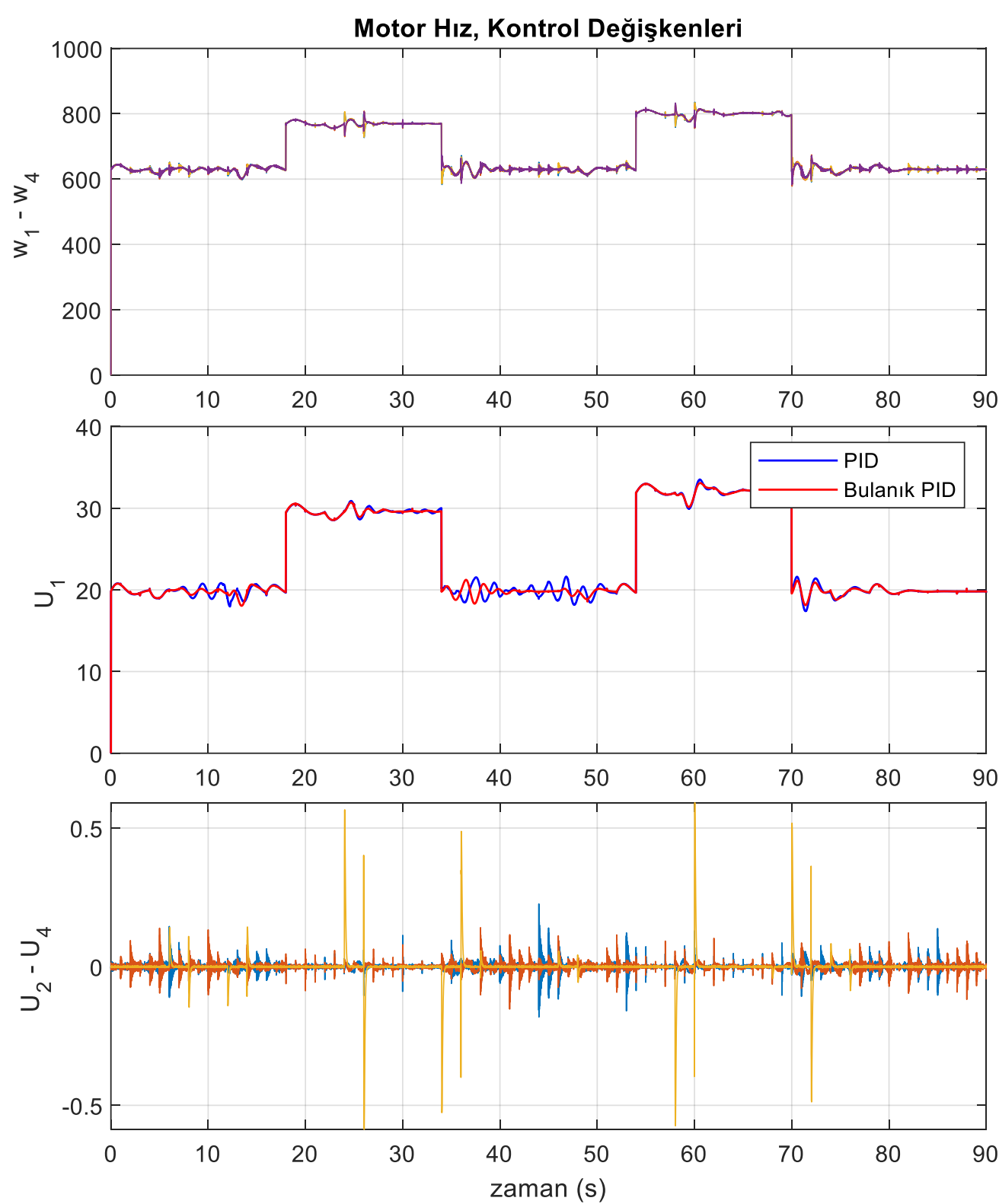

Şekil 7. İHA’nın faydalı yük etkisi ile rota takibinde motor hız ve tork(kontrol değişkenleri) değişimi (Motor speed and torque (control variables) changes in the route tracking of UAV with payload effect)

\section{Sonuçlar (Conclusions)}

Yük taşıma sistemine sahip dört pervaneli İHA'nın belirli bir rotayı takip ederek yük alma ve bırakma görevini minimum hata ile yerine getirebilmesi için bulanık PID denetleyici önerilmiştir. Önerilen bulanık PID denetleyicisinin rota takip performansı karesel hata, toplam yol ve referans $x, y, z$ pozisyonundan sapma değerleri göz önünde bulundurularak analiz edilmiștir. Faydalı yük alma, taşıma ve bırakma görevi esnasında elde edilen sonuçlar incelendiğinde, önerilen bulanık PID denetleyicisinin rota takip performansının PID denetleyici performansına göre yüksek olduğu gözlemlenmiştir. Bu çalışmada önerilen denetleyicinin, yükün alınması ve bırakılması sırasında ağırlık değişiminden minimum seviyede etkilendiği görülmektedir. Farklı ağırlıktaki iki yükün alınma ve taşınma işlemi bu çalışmanın literatürdeki özgünlük değerini ortaya koymaktadır. Yapılan bu çalışmanın sonuçları değerlendirilerek dört pervaneli İHA'nın bulanık PID denetleyicisiyle gerçek zamanlı rota takibi gerçekleştirilip, dış bozucu etkisi incelenebilecektir. Önerilen bulanık PID denetleyicisi, IHHA'larda farklı yük taşıma uygulamalarına kolayca entegre edilebilecektir. Bu çalışmanın sonuçlarından yararlanılarak, yük taşıma sistemine sahip İHA'nın farklı dış bozucu etkiler altındaki denetim performansı incelenebilecektir.

\section{Çıkar Çatışması (Conflict of Interest)}

Yazarlar tarafından herhangi bir çıkar çatışması beyan edilmemiştir. No conflict of interest was declared by the authors. 


\section{Kaynaklar (References)}

Altan, A., Aslan, O., Hacıoğlu, R., 2018. Model Reference Adaptive Control of Load Transporting System on Unmanned Aerial Vehicle. 6th International Conference on Control Engineering and Information Technology, Oct 25-27, 2018, Istanbul, Turkey.

Altan, A., Aslan, O., Hacioğlu, R., 2018. Real-Time Control based on NARX Neural Network of Hexarotor UAV with Load Transporting System for Path Tracking. 6th International Conference on Control Engineering and Information Technology, Oct 25-27, 2018, Istanbul, Turkey.

Altan, A., Hacioğlu, R., 2020. Model Predictive Control of Three-Axis Gimbal System Mounted on UAV for Real-Time Target Tracking under External Disturbances. Mechanical Systems and Signal Processing, 138, 106548.

Gao, Y., Liu, Y. J., 2016. Adaptive Fuzzy Optimal Control using Direct Heuristic Dynamic Programming for Chaotic Discrete-Time System. Journal of Vibration and Control, 22 (2), 595-603.

Lee, T., 2017. Geometric Control of Quadrotor UAVs Transporting a Cable-Suspended Rigid Body. IEEE Transactions on Control Systems Technology, 26 (1), 255-264.

Liu, Y., Wang, Q., Hu, H., He, Y., 2018. A Novel Real-Time Moving Target Tracking and Path Planning System for a Quadrotor UAV in Unknown Unstructured Outdoor Scenes. IEEE Transactions on Systems, Man, and Cybernetics: Systems, 49 (11), 23622372.

Pounds, P. E., Bersak, D. R., Dollar, A. M., 2012. Stability of Small-Scale UAV Helicopters and Quadrotors with Added Payload Mass under PID Control. Autonomous Robots, 33 (1-2), 129-142.

Qiao, J., Liu, Z., Zhang, Y., 2018. Gain Scheduling Based PID Control Approaches for Path Tracking and Fault Tolerant Control of a Quadrotor UAV. International Journal of Mechanical Engineering and Robotics Research, 7 (4), 401-408.

Raffo, G. V., Ortega, M. G., Rubio, F. R., 2011. Path Tracking of a UAV via an Underactuated Control Strategy. European Journal of Control, 17 (2), 194-213.

Rego, B. S., Raffo, G. V., 2019. Suspended Load Path Tracking Control using a Tilt-Rotor UAV based on Zonotopic State Estimation. Journal of the Franklin Institute, 356 (4), 1695-1729.

Ryll, M., Bülthoff, H. H., Giordano, P. R., 2014. A Novel Overactuated Quadrotor Unmanned Aerial Vehicle: Modeling, Control, and Experimental Validation. IEEE Transactions on Control Systems Technology, 23 (2), 540-556.

Shirani, B., Najafi, M., Izadi, I., 2019. Cooperative Load Transportation using Multiple UAVs. Aerospace Science and Technology, 84, 158-169.

Tavakol, F., Binazadeh, T., 2017. Robust Control Design for Path Tracking of Non-Affine UAV. Systems Science and Control Engineering, 5 (1), 474-480.

Villa, D. K., Brandão, A. S., Sarcinelli-Filho, M., 2019. A Survey on Load Transportation Using Multirotor UAVs. Journal of Intelligent and Robotic Systems, 1-30.

Xian, B., Wang, S., Yang, S., 2019. Nonlinear Adaptive Control for an Unmanned Aerial Payload Transportation System: Theory and Experimental Validation. Nonlinear Dynamics, 98 (3), 1745-1760. 